\title{
正则空间的超空间中初始 $\mathbf{m}$ 紧性与局部初始 $\mathbf{m}$ 紧的等价性
}

设 $m \geqslant s_{0}$ ，拓扑空间 $x$ 称为初始 $\mathbf{m}$ 紧的, 只 要每一个基数不超过 $\mathbf{m}$ 的开磷盖有有限子福盖. 在 本文中设 $x$ 为正则空间, $2^{x}$ 表示 $x$ 中所有非空闭子 集合, 赋与有限拓扑.

引五 1 在 $2^{x}$ 中 $X \in\left\langle U_{1}, \cdots, U_{m}\right\rangle$, 其中 $U_{i}$ 在 $X$ 中开. 那么存在 $X$ 中开集 $V_{1}, \cdots, V_{n}$, 使 $X \in$ $\left\langle V_{1}, \cdots, V_{n}\right\rangle \subset\left\langle U_{1}, \cdots, U_{m}\right\rangle$ 且 $\left\{\bar{V}_{1}, \cdots, \bar{V}_{n}\right\}$ 为 $X$ 的 既约盖盖.

引玨 2 设 $2^{x}$ 中闭集, $z \in V, V$ 在 $X$ 中
开. 若 $\mathscr{F} \cap\langle x, \bar{V}\rangle=\phi$, 则集 $\sigma^{*}=\{E \cup\{x\}: E \in$ F) 为 $2^{x}$ 中闭集.

定理 1 设 $m \geqslant s_{0}$ ，则下述等价

1） $2^{x}$ 是初始 $m$ 紧的;

2) $2^{x}$ 是局部初始 $m$ 紧的;

3) 存在 $x$ 在 $2^{x}$ 中邻域 $\mathscr{W}$ 使 $d_{2} x \mathscr{W}$ 是初始 $m$ 紧。

董笑咏王世掠

(内蒙民族师范学院数学系, 通讧)

\section{两个 Schwarzschild 黑洞场迭加对视界固有面积的影响}

前文(科学通报, 28(1983), 12: 716) 讨论了两 个 Schwarzschild 黑洞场迭加的时空结构, 并得出了 视界面积可以减少的结论. 本通讯计算了视界固有 面积并得到了相同的结论.

设有两个分别位于 Weyl 坐标系 $\rho=0, z=0$ 与 $\rho=0, x=Z$ 的 Schwarzschild 黑洞 $m_{1}$ 和 $m_{2}$. 根 据前文 (A.1) 式, 在 $t=$ 常数与 $r_{1}=$ 常数的二维曲 面上,线元为

$$
\begin{gathered}
d s^{2}=\frac{E\left(1,2^{\prime}\right) E\left(1^{\prime}, 2\right)}{E(1,2) E\left(1^{\prime}, 2^{\prime}\right)} \frac{r_{2}^{2}}{r_{2}^{2}-2 m_{2} r_{2}+m_{2}^{2} \sin ^{2} \theta_{2}} \\
\cdot r_{1}^{2} d \theta_{1}^{2}+\frac{r_{1}^{2} \sin ^{2} \theta_{1}}{1-2 m_{2} / r_{2}} d \phi^{2} .
\end{gathered}
$$

\section{易得}

$$
\begin{aligned}
& \left.\frac{E\left(1,2^{\prime}\right) E\left(1^{\prime}, 2\right)}{E(1,2) E\left(1^{\prime}, 2^{\prime}\right)}\right|_{r_{1}=m_{1}} \\
& \quad-\left[\frac{\left(Z-m_{2}-z\right)\left(Z+m_{1}+m_{2}\right)}{\left(Z+m_{2}-z\right)\left(Z+m_{1}-m_{2}\right)}\right]_{r_{1}=2 m_{1}}^{2}
\end{aligned}
$$

度规(1)的行列式为

$$
\left.\boldsymbol{g}\right|_{\rho_{1}=2 m_{1}}=\left[4 m_{1}^{2} \sin \theta_{1} \frac{Z+m_{1}+m_{2}}{Z+m_{1}-m_{2}}\right]^{2} .
$$

当 $z \geqslant m_{1}+m_{2}$ 时, 黑洞 $m_{1}$ 视界的固有面积为

$$
\begin{aligned}
A_{1} & =\int_{0}^{2 \pi} \int_{0}^{\pi}\left[\left.g\right|_{r_{1}=2 m_{1}}\right]^{1 / 2} d \theta_{1} d \phi \\
& =16 \pi m_{1}^{2} \frac{Z+m_{1}+m_{2}}{Z+m_{1}-m_{1}} .
\end{aligned}
$$

由前文的定理知, $r_{1}=2 m_{1}$ 与 $r_{2}=2 m_{2}$ 同时成 立的区域不再是视界. 根据类 Zipoy 变换

$$
z=\left(r_{1}-m_{1}\right) \cos \theta_{1}=\left(r_{2}-m_{2}\right) \cos \theta_{2}+z,
$$

可得到当 $Z \leqslant m_{1}+m_{2}$ 时在黑洞 $m_{1}$ 的视界上 $\theta_{1}$ 的 值域为

$$
\pi \leqslant \theta_{1} \leqslant \arccos \frac{Z-m_{2}}{m_{1}} .
$$

于是, 当 $z \leqslant m_{1}+m_{2}$ 时黑洞 $m_{1}$ 视界的固有面积为

$$
\begin{aligned}
A_{1} & =\int_{0}^{2 \pi} \int_{\operatorname{arccot}}^{*} \frac{z-m_{2}}{m_{1}}\left[\left.g\right|_{r_{1}=2 m_{1}}\right]^{1 / 2} d \theta_{1} d \phi \\
& =8 \pi m_{1}\left(Z+m_{1}+m_{2}\right) .
\end{aligned}
$$

由(4)与(6)式可知, 当 $Z=m_{1}+m_{2}$ 时黑洞 $m_{1}$ 视界的固有面积达到极大值 $16 \pi m_{1}\left(m_{2}+m_{2}\right)$, 此后 当 $z$ 减小时视界面积将减少，类似，我们可计算黑 洞 $m_{2}$ 视界的固有面积, 同样的结论对黑洞 $m_{2}$ 也是 对的. 因此我们得出结论, Schwarzschild 黑洞视界 的固有面积可以减少.

王永成 (北京师范大学物理系) 